\title{
Structural Analysis of Biologically Inspired Small Wind Turbine Blades
}

\author{
Cory Seidel, Sanjay Jayaram ${ }^{*}$ (D, Leah Kunkel and Alexander Mackowski
}

\begin{abstract}
Background: Renewable energy resources are becoming more important to meet growing energy demands while reducing pollutants in the environment. In the current market, wind turbines are primarily restricted to rural use due to the large size, noise creation, and physical appearance. However, wind turbines possess the ability to run at any time of the day. Horizontal axis wind turbines remain the most widely used, but there is significant room for improvement in vertical axis wind turbines.
\end{abstract}

Methods: While vertical axis wind turbines are not reaching the same level of efficiency of horizontal axis wind turbines, there are significant benefits to researching improvements. One of the main benefits is to make use of vertical axis wind turbines in urban settings. In order to improve the efficiency of the vertical axis wind turbine, a biological approach was taken to design blades that mimic the shape of maple seeds and triplaris samara seeds. This approach was taken because due to its geometrical properties, typically extra lift is generated.

Results: The results obtained through FEA simulations were consistent with the expected results for the application that was considered. The results obtained provide valuable insight for engineers to iterate and design optimum wind turbine blades taking advantage of biological phenomena applied to conventional airfoils.

Conclusions: The purpose of this paper is to provide structural analysis details into the design of a vertical axis wind turbine blades that mimic the geometry of maple and triplaris samaras seeds.

Keywords: Wind energy, Wind turbine, Maple seed, Renewable energy, Tubercle

\section{Background}

Increasing demands for energy and green engineering is leading to an increase in generation of renewable energy from resources such as solar, wind, and hydroelectric power. While solar energy is currently the most commercially used, wind energy has enormous potential for increase in efficiency and power output (Maehlum 2016). Further, vertical axis wind turbines have the potential to outperform horizontal axis wind turbines but have not achieved the maximum efficiency available (Dabiri 2011). This has led to more research into commercial applications of vertical axis wind turbines. While not all locations are ideal for wind turbines, they do hold an advantage over solar panels in that they can work constantly because they are not dependent on the sun being present (Boyle 2012).

\footnotetext{
* Correspondence: sjayaram@slu.edu
} Saint Louis University, St. Louis, USA
Wind turbines are divided into two major groups, vertical axis wind turbines (VAWTS) and horizontal axis wind turbines (HAWTS). By definition, VAWTS rotate about an axis that is vertical to the air flow. Likewise, HAWTS rotate about an axis that is horizontal to the flow of air. VAWTS are divided into two types: lift driven and drag driven. As the name suggests lift-driven VAWTS rotate due to lift forces generated by air flowing over the blades. Lift-driven VAWTS are sometimes referred to as Darrieus wind turbines because it is the most well-known of the lift-driven turbines, but other lift-driven wind turbines do exist and are used in research and energy generation. Drag-driven VAWTS are commonly known as Savonius wind turbines, which is the most common drag-driven VAWT. While different shapes of blades exist for these types of turbine, they all follow the same idea of scooping the wind. Examples of both types of VAWTS are shown below in Fig. 1. Unlike VAWTS, HAWTS are not generally further categorized 


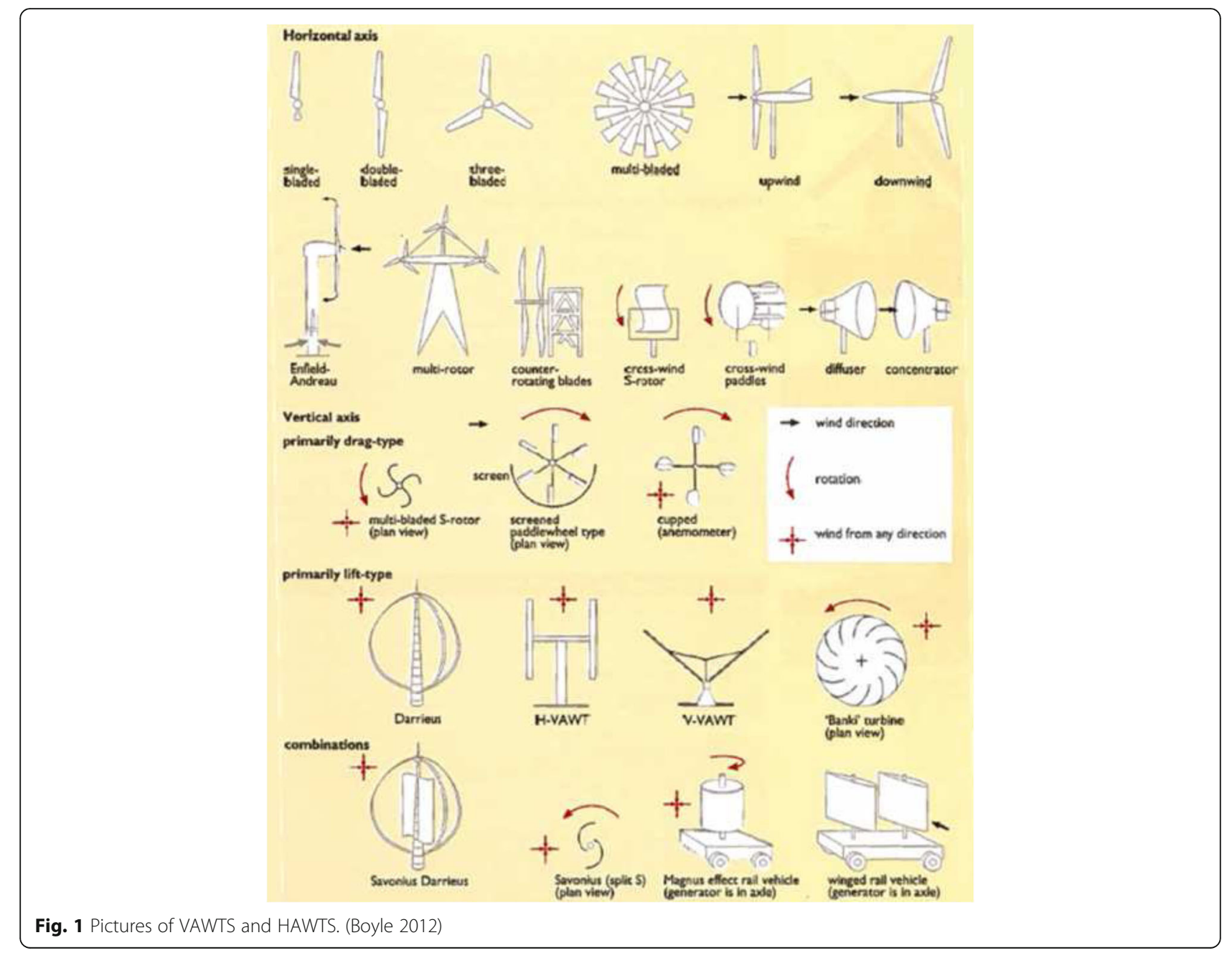

because they are all driven in the same way. While many variations exist in HAWTS from blade shapes to axis formations, there is not enough to create subcategories.

The current market is primarily HAWTS, but VAWTS have shown the ability to provide more energy per land area, or a greater power density. The power density for a VAWT wind farm can achieve a magnitude of ten times greater than a HAWT wind farm (Dabiri 2011). The increase in power density is due to the ability of VAWTS to be placed closer together than HAWTS. If a wind turbine is too close to the next wind turbine, the airflow will be disrupted and impact the power output. The placement of wind turbines to improve power output is important but only has a major impact when turbines are in close proximity of one another. Single turbine efficiency is still the major selling point, especially in individual use and urban settings. The current major drawback in VAWTS is the overall lower efficiency compared to the efficiency of HAWTS. However, VAWTS have the advantages of being able to rotate at lower wind speeds, ability to function on wind from any direction, and are located lower to the ground, which reduces cost and can be more marketable for urban settings (Boyle 2012; Tummala et al. 2016).

\section{General overview}

In an attempt to improve the efficiency of VAWTS, several biological phenomena were studied and applied to a small VAWT. The first biological factor studied was that

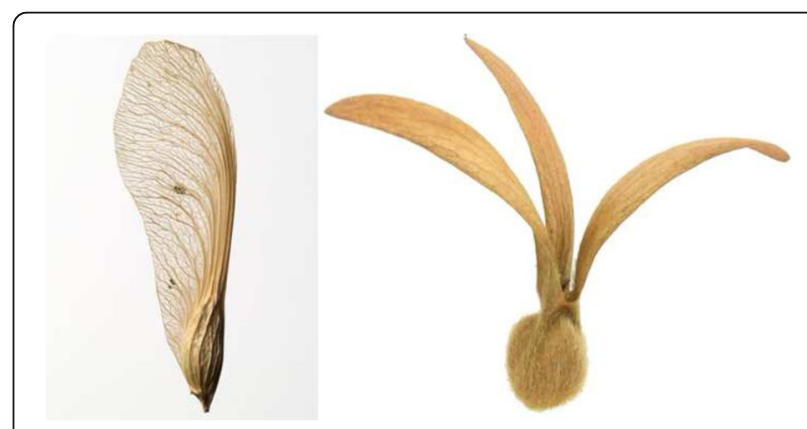

Fig. 2 Maple seed (left) and triplaris samara seed (right) 
of the lift generation of maple and triplaris samara seeds (Fig. 2). It has been shown that the seeds generate stable leading-edge vortices (LEV) that increase the lift force while descending (Lentink et al. 2009). Although a wind turbine will not be descending, it is thought that imitating the geometry of the wing portion of the seeds and converting them into blades will increase the lift generated by the VAWT and thus increase the efficiency. It was also shown that the LEV, which is generated near the base of the wing, is reliant upon the geometry of the wing, Reynolds number, and angle of attack (Lentink et al. 2009). The drawback of generating a LEV is an increase in drag. The lift-to-drag ratio is naturally maximized by the seeds through change in angle of attack (Pandolfi and Izzo, 2013). Unless the turbine is overly complex, the automatic adjustment cannot be made. Therefore, the patterns of the angle of attack and pitch for falling seeds were studied and applied. Further testing into optimizing the lift-to-drag ratio will be done through physical testing and computational analysis.

Even though the lift-to-drag ratio can be optimized, the increased drag generated by the LEV causes a loss in efficiency. The second biological aspect studied and applied to the FEA simulations was the structural analysis of whale tubercles (Fig. 3). More specifically, the tubercles under observation are similar to those found on the leading edge of humpback whale flippers. Tubercles are large, round growths that improve a humpback whale's ability to maneuver and catch prey through increased performance (Fish et al. 2011). The improved performance is caused by an increase in maximum lift and a decrease in drag (Fish et al. 2011). Theoretically, the increased lift will further improve the maximum power output and the drag reduction will improve the efficiency. It is difficult to generate the geometry of the tubercles because they are inconsistent in shape and vary from whale to whale. Therefore, a pattern was created to best imitate the tubercles on a humpback whale.

\section{Technical Approach/Methods}

\section{Generation of FEA models}

All the simulation work was completed using ABAQUS CAE software. Prior to conducting FEA simulations, the

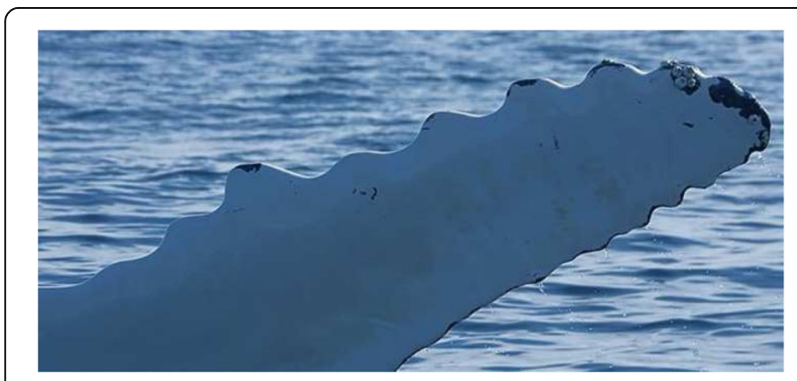

Fig. 3 Whale tubercle. (AskNature 2016) turbine blade size and geometries should be designed. While the turbine shaft was not as important as the blade designs, it was still desired to be designed efficiently to reduce the force required to get the turbine to rotate but strong enough to withstand high winds. Additional considerations were given to the size required for the desired application. As mentioned previously, the project is to design a VAWT that is small scale, designed to be used in an urban environment for things such as powering sensors on bridges and streetlights. That being said, the designed turbine measured about $30 \mathrm{~cm}$ in height and a blade length of about $16 \mathrm{~cm}$. In addition, the initial prototypes were desired to be made of plastics through 3D printing (Object Eden260V from Stratasys). The 3D printing process allows for easy creation of prototypes; however, the thickness of the layers became an issue. Future physical testing was taken into consideration during FEA model creation to ensure values could be compared with a high degree of confidence. In particular, size of experimental rotors was limited by the size of wind tunnel test chamber. Parameters that were considered to be included in the sizing limitations were distance between the blade tip and wall and height of blades in the tunnel. The wind tunnel data can be scaled appropriately, depending on the Reynolds number conditions, for future FEA models of larger wind turbines.

Several different airfoils were tested prior to determining that the NACA 0012 airfoil was the best choice of the selected design (Fig. 4). While the NACA 0012 airfoil did not have the highest coefficient of lift, it structurally outperformed the other options to the extent of deflecting about $60 \%$ less at equivalent pressure loadings. After the desired airfoil was selected, the different blade types were generated.

The FEA simulations were broken down into nine groups to validate the results and impact of the blade geometries. The groups were normal blades, extended normal, maple seed shape, triplaris samara seed shape, normal with tubercles, extended normal with tubercles,

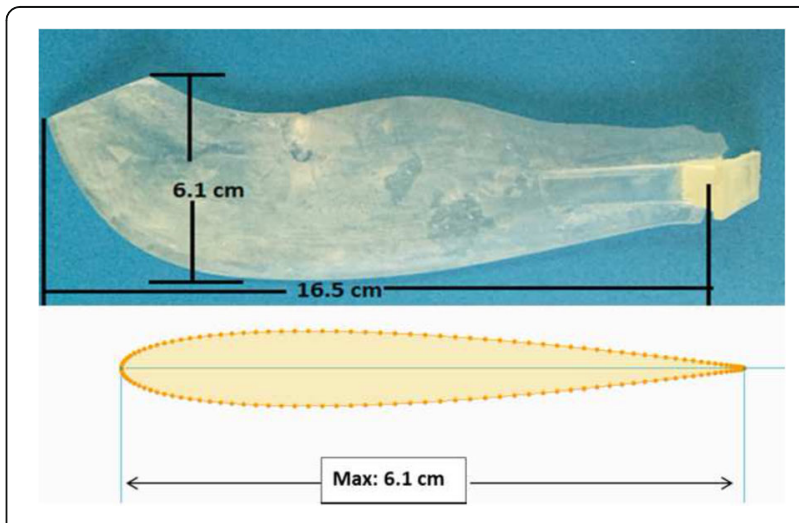

Fig. 4 3D printed airfoil and NACA 0012 blade cross-section 
maple seed with tubercles, triplaris samara with tubercles on the leading edge, and triplaris samara with tubercles on the trailing edge. The normal blades are straight blades with a constant cross-section width. The extended normal blades were designed similar to the normal blades with the only difference being the length of the blade. The blade length was extended to have the same surface area for the lower half of the blade as the maple seed blade to compare the structural integrity for the same pressure application over the same area. The maple seed blade was designed to follow the geometry of a maple seed as close as possible to generate leadingedge vortices and increase the lift of the wind turbine. The cross-section of the maple seed was difficult to generate and would not be reliable at high wind speeds. Given that the wind turbine is lift driven, the use of airfoils was determined to be the best option. The triplaris samara blades were designed in a similar fashion as the maple seed blades.

After the first four blade types were generated, tubercles were added to each blade. The tubercles were added to increase lift and reduce drag while not sacrificing structural integrity. In addition to the tubercles, each of the blades was set up for angles of attack of both 0 and $7^{\circ}$ and two pitch angles for the entire blade of 0 and $23^{\circ}$ (Fig. 5). The two angles of attack were selected to both create a baseline at zero and to create the max coefficient of lift at the $7^{\circ}$ angle (Airfoiltools.com. 2016). While the $0^{\circ}$ pitch angle was chosen as a baseline for future studies on the lift generation, it also serves a purpose in determining if the pitch angle impacts the structural integrity. However, the second pitch angle of $23^{\circ}$ was picked based on previous research to match the pitch of a maple seed as it freely falls and rotates (Lentink et al. 2009). The triplaris samara blades were designed with varying twist angles for each of the blades. These angles were set at $0,7,12$, and $15^{\circ}$. For the purposes of this portion of the research, the angles were selected to show the variation, if any, in displacement and stress. These angles were also selected for future work

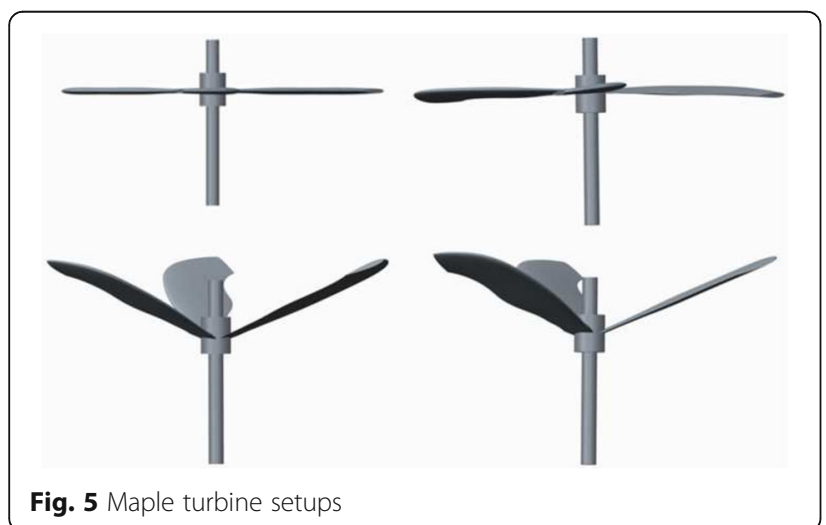

and the determination of lift generation and fluid flow patterns.

\section{Results and Discussions \\ FEA simulation and results}

Several loading setups for the FEA testing were considered and researched to determine the loading that a liftdriven VAWT would undergo. Through speculation and consultation of numerous sources, it was determined that the worst case scenario for maximum loading without considering fatigue would occur if the turbine were to stall and all blades had a pressure applied to the under surface (the lifting force) (Ragheb 2008; WindPower.org 2016; Chou et al. 2013) While this is not the most common scenario, it would provide whether or not the turbine could survive stalling at various speeds. Boundary conditions were applied such that the base of the shaft was constrained in all translational directions (Fig. 6). 3D solid elements were used in the system, which made rotational constraints unnecessary. Combined, these aspects created an environment similar to that of a stalled rotor.

Assumptions for FEA analysis/Geometry:

- Fixed rotationally through 3D solid elements

- Blades and shaft are all one piece (no friction)

- Geometry of blade was not simplified for symmetry or axi-symmetry

- Geometry of blade attachment was simplified to remove issues with contact of mounting system and turbine shaft

- Focus was on blade and not attachment mechanism

Under these conditions, three of the same kind of blade were attached to a shaft and tested for the maximum von Mises stress and the maximum displacement.

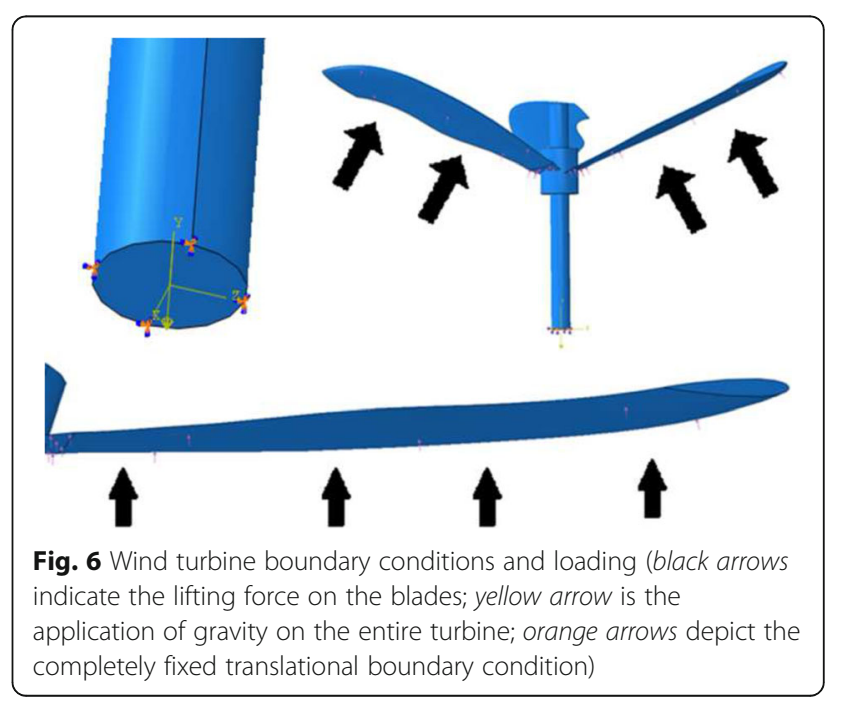


Table 1 ABS Plastic material properties (Comparison of Typical 3D Printing Materials n.d.)

\begin{tabular}{ll}
\hline Density $\left(\mathrm{Mg} / \mathrm{m}^{3}\right)$ & $1.01-1.21$ \\
Young's modulus E (GPa) & $1.1-2.9$ \\
Ultimate tensile strength $(\mathrm{MPa})$ & $33-110$ \\
\hline
\end{tabular}

The contact surface between the blades and shaft were considered to be attached (no frictional contact stress). Maximum von Mises stresses were compared to the ultimate tensile strength of ABS plastic and to maximum stresses in other blade types. The theoretical material values for ABS plastic are located in Table 1. The displacements of the blades were mostly compared to one another to determine the impact of shape and tubercles on rigidity of the structure. Normal blades were considered to be a baseline for comparison of changes in displacement and stress.

An initial basic mesh optimization was completed only on the maple seed and samara blades with at the zero angle of attack and zero pitch orientation with a wind speed of $15 \mathrm{~m} / \mathrm{s}$. For both blade types, the number of elements for each optimization level was as follows: coarse mesh of $\sim 70,000$ elements, moderate mesh of $\sim 150,000$ elements, fine mesh of $\sim 200,000$ elements, and very fine mesh of 250,000 elements. Ultimately, the data demonstrated small changes between the fine and very fine mesh patterns. An intermediate fine mesh $(\sim 220,000$ 230,000 elements) was used to ensure quality output while decreasing the simulation time. Tetrahedral elements were used throughout the entire model as they adapted best to the geometry of the blade.

There were no geometric simplifications applied to the blade itself or the applied loading. The mounting system was simplified to overcome the issues with contact of the mount mesh and shaft mesh. Without this simplification, the resolution of the mesh would have needed significant refinements, resulting in greater time requirement to complete simulations. The attachment method

Table 2 Wind speeds and corresponding pressure loads

\begin{tabular}{ll}
\hline Wind speed $(\mathrm{m} / \mathrm{s})$ & Pressure load $(\mathrm{Pa})$ \\
\hline 10 & 31 \\
15 & 69 \\
20 & 123 \\
25 & 192 \\
30 & 276 \\
35 & 376 \\
40 & 490 \\
45 & 621 \\
50 & 766 \\
55 & 927 \\
\hline
\end{tabular}

utilized was determined to provide a better analysis of the blade behaviors without bias in data from mounts.

Simulations were performed varying the pressure values corresponding to $5 \mathrm{~m} / \mathrm{s}$ increments in wind speed (see Table 2). To determine the pressure load on the blade surface, the general lift equation was rearranged to obtain

$$
\frac{L}{A}=\frac{1}{2} C_{L} \rho v^{2}
$$

Where the pressure load is equal to the lift force, $L$, divided by the surface area of the bottom surface of the blade. Surface area was determined through a measurement tool in Creo Parametric. The lift coefficient was appropriately correlated through known NACA 0012 data.

The range of pressures was selected to cover a sufficient array of loadings that wind turbine blades would typically experience. Since the likelihood of higher wind speeds in urban setting is extremely low, it is deemed important to demonstrate ability or inability of the blades to withstand the wind loading conditions so as to meet performance benchmarks of commercial wind turbines. Analysis was completed for static loading to show a correlation between blade geometry and orientation to determine the loading patterns of each blade. Future work in this area will include cyclic loading conditions, which will give a better perspective to further narrow down orientations and geometries. In addition, cyclic loading will be utilized to analyze fatigue life and failure of blades. The premise of this work was to lay the foundation for different blade geometries and to understand the pressure and stress distribution as well as rigidity of geometries.

The simulation analysis was performed for static loading to show a correlation between blade geometry and orientation to determine the loading patterns of each blade. Future work in this area will include cyclic loading conditions, which will give a better perspective to further narrow down orientations and geometries. Along with cyclic loading, fatigue and failure will also be discussed in future work. The premise of this work was to lay the foundation for different blade geometries and to understand the pressure and stress distribution as well as rigidity of the geometries. The limitations of this study:

- Preliminary study of stress distribution across the varying blade geometries

- Not loaded cyclically, future considerations to fatigue and failure

- Experimental validation has not yet been completed

\section{Discussion of results}

When comparing the maple leaf turbine blades to the normal blades (Figs. 7 and 8), the variation in displacements 


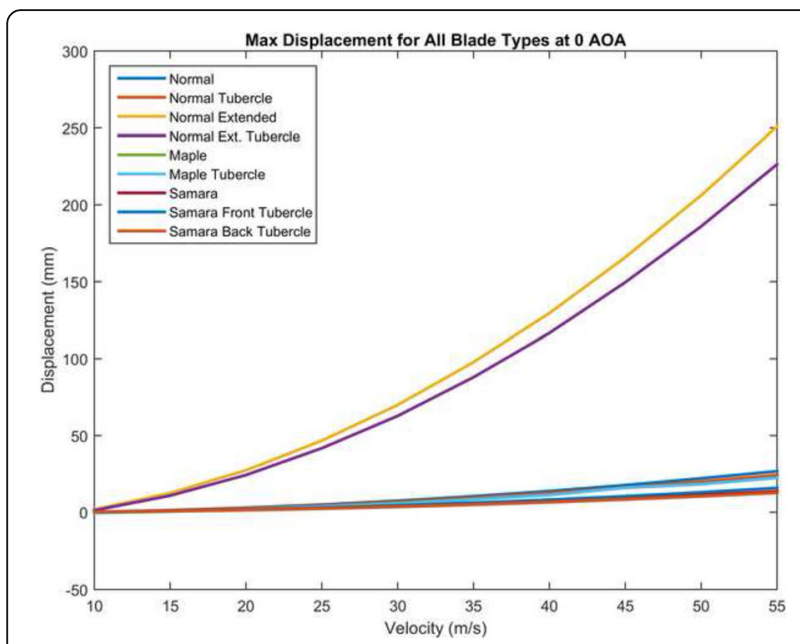

Fig. 7 Max displacement for all blade types at $0^{\circ}$ angle of attack

showed a significant increase as the velocity increased. While numerically the percentages are fairly large at the lower velocities, the maple seed blades showed the ability to withstand stronger wind speeds. It was noticed that at the $10 \mathrm{~m} / \mathrm{s}$ wind speed, the maple seed blades actually deflected downward. This was attributed to the fact that the lifting force generated by the air flow was not strong enough to counter the gravitational force generated by the mass of the maple seed blade. However, the normal blades did not experience negative displacements at the $10 \mathrm{~m} / \mathrm{s}$ wind speed. This trend was justified by the fact that the normal blade and maple seed blade had different masses, impacting the force of gravity on the blades. It should also be pointed out that the deflection in the blades for this velocity was in the range of fractions of a millimeter. The geometry of the maple seed is also configured in a way that the cross-section is thicker in the wider portion of the blade, which will further increase the strength to

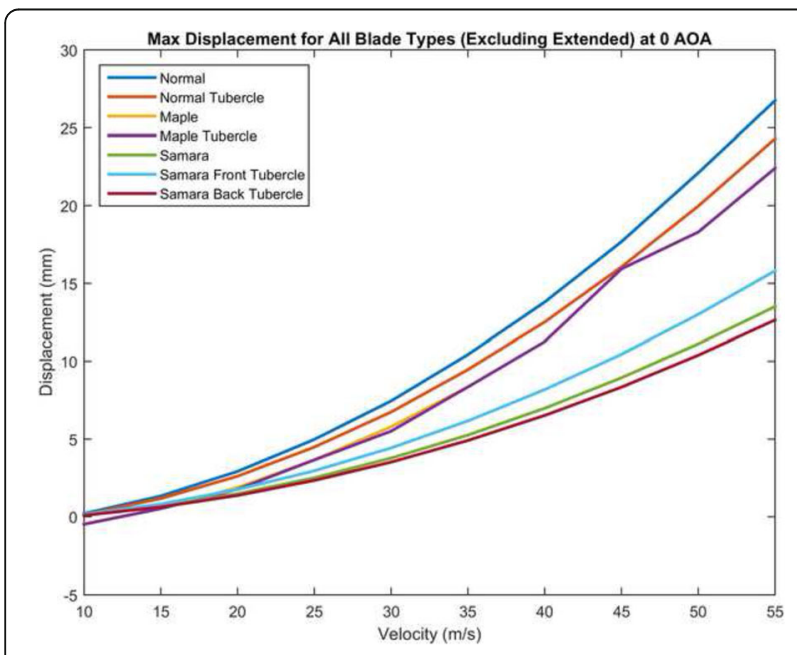

Fig. 8 Max displacement for all blades excluding normal extended withstand higher wind speeds. This trend was especially evident in the blades at higher wind speeds. As noted previously, there is a much greater difference in the displacement between the maple seed blades and the normal blades. All of the types of blades showed significant improvement compared to the normal extended blades, and the samara seed blades showed the best structural properties.

In order to compare the maple seed blade to a blade with the same surface area, the normal blade was extended to achieve the same surface area. The amount of lift generated is directly related to this surface area and therefore allows for a comparison to determine which blade is structurally stronger for the same lift generation. The maple seed blade proved to be stronger for all of the blade configurations except for the maple seed with zero angle of attack and zero pitch angle. However, all of the blades showed much lower deflections than the extended normal blades. When comparing the maple seeds to one another (Figs. 9 and 10), it was shown that the greatest reduction in stress and displacement for the blades occurred at an angle of attack of $7^{\circ}$ and a pitch of $23^{\circ}$. While the angle of attack was chosen to produce a large coefficient of lift, the pitch angle was used based off of studies on the angle at which maple seeds fall (Lentink et al. 2009). This trend provided insights into the physics behind falling maple seeds and the impact of the pitch angle on the structural integrity. It was also noticed that for some velocities, the maple blade with an angle of attack of zero and a pitch of 23, the reduction in displacement was the lowest and the increase in stress increased more than any of the other blades. For the $10 \mathrm{~m} / \mathrm{s}$ tests of the maple seed blades, the maximum stress and displacement did not follow the same trends. This was determined to be due to the fact that the lift generated by the wind was not enough to fully counter the weight of the blade.

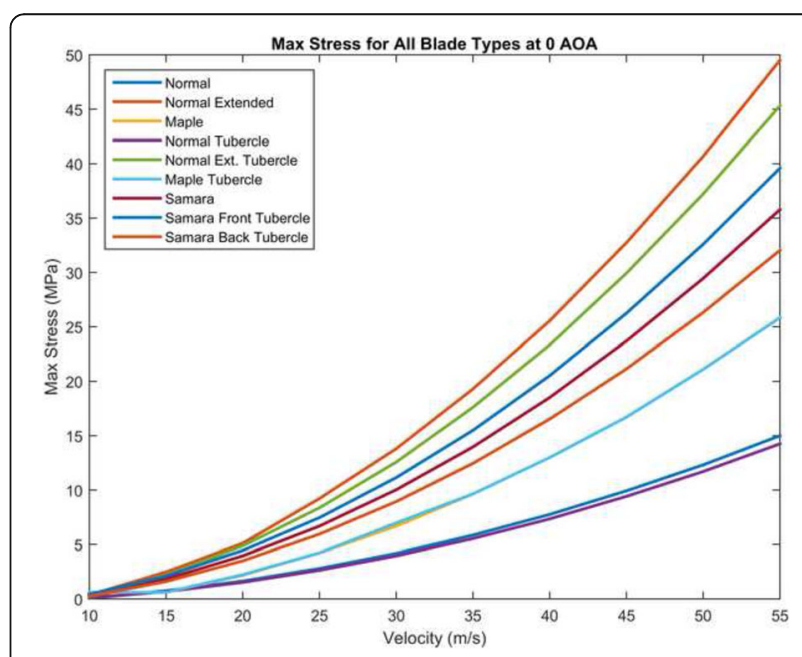

Fig. 9 Max displacement of maple blades 


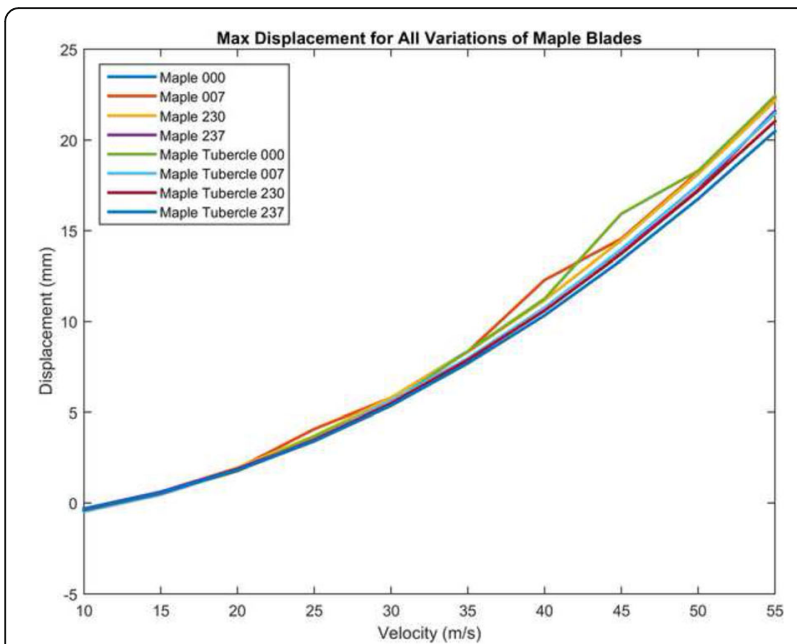

Fig. 10 Max stress for maple blades

While the triplaris samara blade can be compared to the normal blades, it cannot be compared as closely as the maple blades. This lesser comparison value is due to the fact that the samara blades have a different geometry and orientation than the normal blades, but the general trends can be compared as well as the trends for the addition of tubercles. As is shown in Figs. 11 and 12, the samara blades with the tubercles on the trailing edge (Samara BT) had the lowest max stress and max displacement. However, the blade with tubercles on the leading edge in general had the largest max displacement and max stress. For comparison purposes, the samara blades showed the lowest max displacement of all of the blade types (Figs. 7, 8, and 13). However, the samara blades do not have the lowest max stress. This implies that the geometry of the samara blades is not as

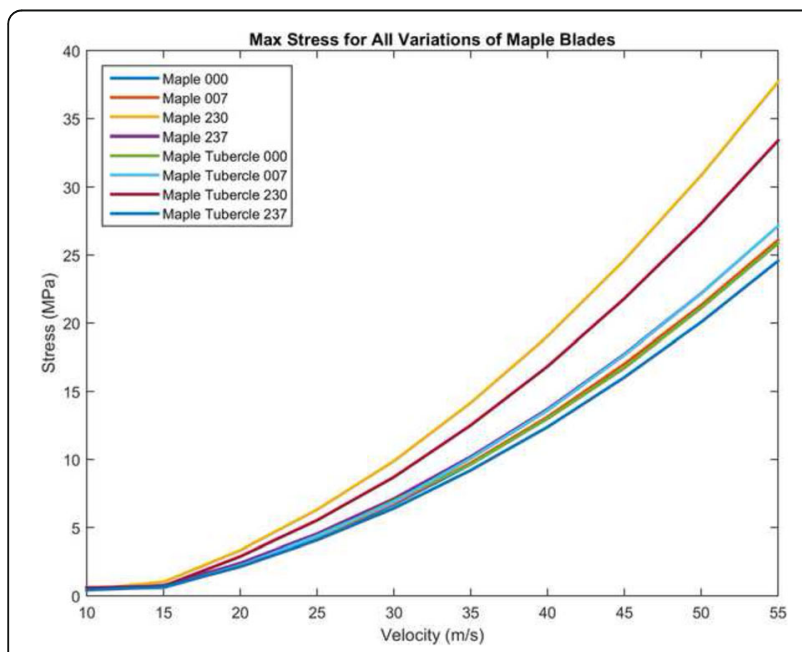

Fig. 11 Max displacement for samara blades

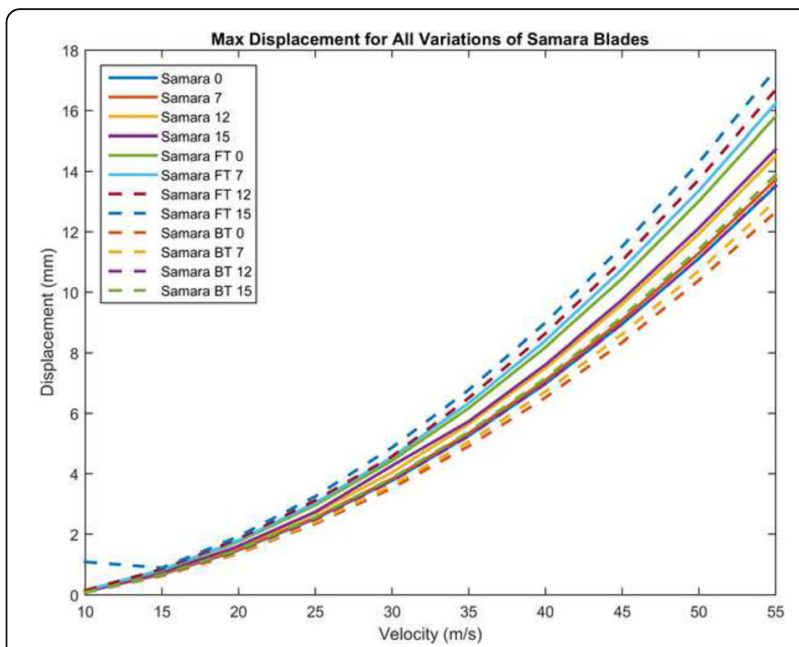

Fig. 12 Max stress for samara blades

structurally sound as the maple blades. Examples of the stress profiles can be found in Fig. 14.

Addition of tubercles to the blades was done with the intent of decreasing the drag and at the same time increasing the lift-to-drag ratio without sacrificing structure stability of the blades. When comparing the normal blades with and without tubercles, it was shown that the blades with tubercles had lower maximum stresses and displacements. This proved the tubercles did not lose any structural strength. The same was true for the extended normal blades with tubercles and without. Comparing the maple blades, there was a slight increase in maximum stress for the maple seed blades with tubercles. However, a majority of the maple blades with tubercles showed a decrease in displacement. These were also small changes. If CFD simulations were to show an increase in lift and

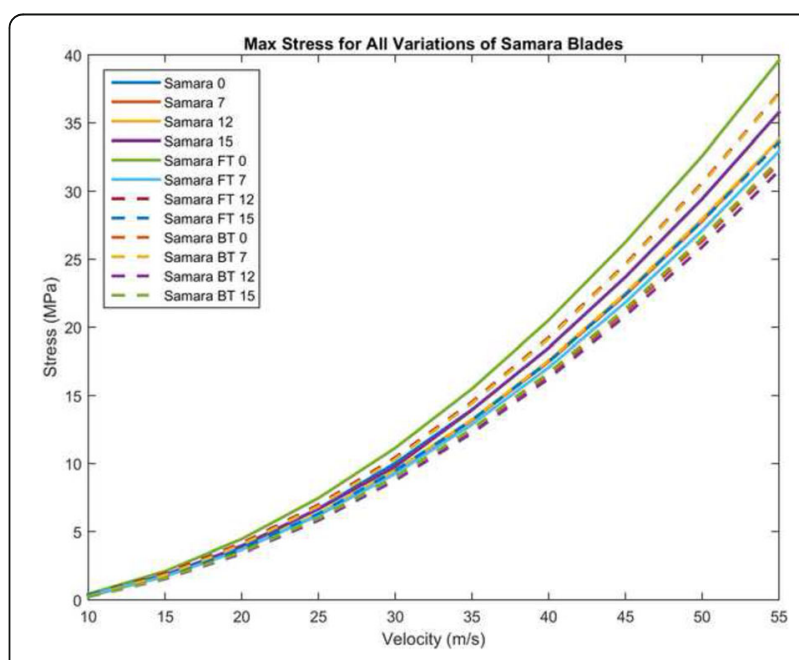

Fig. 13 Max stress for all blade types 


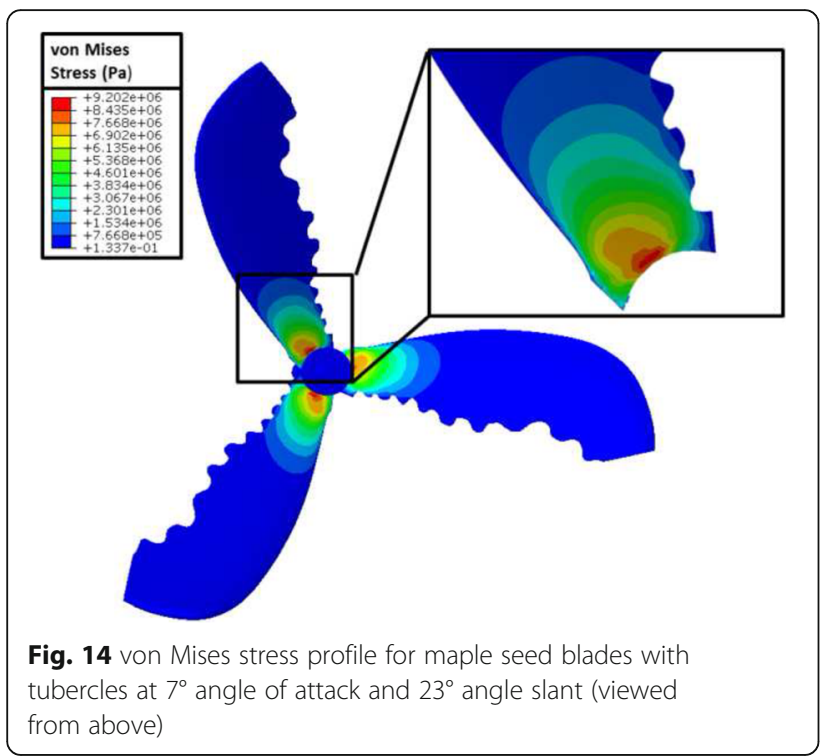

decrease in drag, the changes would be enough to consider the tubercles successful.

\section{Conclusions/Summary}

This paper presented the initial design, blade analysis, and proposed physical creation of the micro wind turbine and blades. Due to the desire for a small wind turbine for urban applications, the proposed design was the actual size of the wind turbine. Removing the scaling provides a direct comparison, which is ideal for the number of variations applied to the modeling. The small size also allows for easy physical creation through 3D printing and injection molding. While physical testing has not yet occurred, the consideration of future testing taken during creation of the model will make it much easier to handle. The FEA analysis of the application of maple seed and triplaris samara seed wing geometry to wind turbine blades proved to be insightful. It was shown that structurally the wind turbine blades could withstand strong wind speeds of up to $55 \mathrm{~m} / \mathrm{s}$, while proving to be structurally comparable, and in many cases superior, to the strength of the normal blade. In addition, it was shown that the maple seed blades actually deflected less than the normal blades. Further modification gave a baseline justification that addition of tubercles would not hurt the structural integrity of the blades. While there were some increases in the stress felt by the blades, the deflection actually decreased in most blades. These results proved that more work should be done in the investigation on the impact of tubercles in the power generation of the blades.

This work will be applied to future FEA and CFD work on the micro wind turbine. Now that the structural improvements have been noted, several cross-sections will be tested for structural validation. It is important to validate this prior to CFD simulations. Physical testing will also occur to validate the structural strength of the design and compare the results. In addition, the amount of lift and power generated will be measured and compared to the CFD and FEA models.

\begin{abstract}
Authors' contributions
CS made substantial contributions to the study specifically in the conception, design and running most of the simulation analysis. He also mentored the two undergraduate students who are co-authors. CS analyzed the simulation results and interpreted data. CS verified the simulation results obtained by the two undergraduate students. CS was involved in drafting of the manuscript as well as revising it critically for important intellectual content. SJ mentored the main author (CS) during his graduate studies and analyzed and verified the development of the concept, theory, and design as well as simulation results. SJ was involved in drafting of the manuscript as well as revising it critically for important intellectual content. LK contributed in the development of the concept and understood the theory behind the concept. LK was involved in creating some of the test case models, ran the finite element analysis, and acquired the simulation data. LK was involved in drafting of the manuscript. AM contributed in the development of the concept and understood the theory behind the concept. AM was involved in creating some of the test case models, ran the finite element analysis, and acquired the simulation data. AM was involved in drafting of the manuscript. All authors read and approved the final manuscript.
\end{abstract}

\section{Competing interests}

The authors declare that they have no competing interests.

\section{Publisher's Note}

Springer Nature remains neutral with regard to jurisdictional claims in published maps and institutional affiliations.

Received: 6 July 2017 Accepted: 12 July 2017

Published online: 22 August 2017

\section{References}

Airfoiltools.com. (2016), NACA 0012 AIRFOILS (n0012-il), available at: http:// airfoiltools.com/airfoil/details?airfoil=n0012-il (Accessed 12 Apr 2016).

AskNature. (2016). Flippers provide lift, reduce drag: Humpback whale. Available at: http://www.asknature.org/strategy/3f2fb504a0cd000eae85d5dcc4915dd4 (Accessed 23 Apr. 2016).

Boyle, G. (2012). Renewable energy: power for a sustainable future. Oxford: Oxford University Press.

Chou, J., Chiu, C., Huang, I., \& Chi, K. (2013). Failure analysis of wind turbine blade under critical wind loads. Engineering Failure Analysis, 27, 99-118.

Comparison of Typical 3D Printing Materials. (n.d.). 1st ed. Available at: http://2015. igem.org/wiki/images/2/24/CamJIC-Specs-Strength.pdf (Accessed 4 Mar 2016).

Dabiri, J. (2011), Potential order-of-magnitude enhancement of wind farm power density via counter-rotating vertical-axis wind turbine arrays, Journal of Renewable and Sustainable Energy, 3(4), p.043104. (http://dx.doi.org/10.1063/ 1.3608170).

Fish, F., Weber, P., Murray, M., \& Howle, L. (2011). The tubercles on humpback Whales' flippers: application of bio-inspired technology. Integrative and Comparative Biology, 51(1), 203-213.

Lentink, D., Dickson, W., van Leeuwen, J., \& Dickinson, M. (2009). Leading-edge vortices elevate lift of autorotating plant seeds. Science, 324(5933), 1438-1440.

Maehlum, M. (2016). Wind Energy Pros and Cons. [online] energy informative. Available at: http://energyinformative.org/wind-energy-pros-and-cons/ [Accessed 9 Feb. 2016].

Pandolfi, C., \& Izzo, D. (2013). Biomimetics on seed dispersal: survey and insights for space exploration. Bioinspiration \& Biomimetics, 8(2), 025003.

Ragheb, M. (2008), Dynamics and structural loading in wind turbines, 1 st ed. available at: http://mragheb.com/ NPRE\%20475\%20Wind\%20Power\%20Systems/ Dynamics\%20and\%20Structural\%20Loading\%20in\%20Wind\%20Turbines.pdf (Accessed 19 May 2016). 
Tummala, A., Velamati, R., Sinha, D., Indraja, V., \& Krishna, V. (2016). A review on small scale wind turbines. Renewable and Sustainable Energy Reviews, 56, 1351-1371.

WindPower.org. (2016), Wind turbine design: basic load considerations, available at: http://xn\%2D-drmstrre-64ad.dk/wp-content/wind/miller/windpower\%20web/ en/tour/design/index.htm (Accessed 19 May 2016).

\section{Submit your manuscript to a SpringerOpen ${ }^{\bullet}$ journal and benefit from:}

- Convenient online submission

- Rigorous peer review

- Open access: articles freely available online

- High visibility within the field

- Retaining the copyright to your article

Submit your next manuscript at $\gg$ springeropen.com 